\title{
Nitrogen and the Carrying Capacity of the Earth
}

\author{
Enriching the Earth: Fritz, Haber, Carl Bosch, and the Transformation \\ of World Food, by Valclav Smil. Cambridge, Mass.: MIT Press, 2001
}

\author{
Joseph L. Fail Jr.
}

Published online: 4 July 2009

(C) Springer Science + Business Media, LLC 2009

What would be the population of the earth without "enrichment?" If that sounds like a strange question, consider the answer-perhaps three billion persons less than we have now, and that is because we would not have the food to feed us without the technology of soil nutrient enrichment. Vaclav Smil has written an excellent and crisply focused science and history story on the broader subject of human domination of the biosphere through agriculture. It is because of the discovery of the technical means to split the molecule of nitrogen - the most abundant element in the atmosphere and yet often most limiting in the soil home of the plant-which, thus, makes it reactive and so crucial in all of life's processes. Left to nature, this enrichment could not occur, and human population numbers would be at levels - carrying capacities - that nature decrees. Exceeding natural carrying capacities for long terms has very certain ecological impacts and may also have evolutionary ones as well, such as causing species extinctions.

Smil sets the stage for his story by providing a history of nineteenth century European scientists who were trying to make sense of the cycle by which the most important of agricultural elements is transformed from its immense yet chemically inert atmospheric elemental pool (the energetics and physics of why this inertness occurs is not explained) to its relatively tiny but crucially active pool of chemical compounds that make life possible. As if to taunt modern scientists for their focus on narrow biological problems, he quotes from the ecological insight of Justus von Liebig in his 1840 book on the relationship of chemistry to

J. L. Fail Jr. $(\bowtie)$

Department of Natural Sciences, Johnson C. Smith University, Charlotte, NC 28216, USA

e-mail: jfail@jcsu.edu agriculture and forestry: "Agriculture differs essentially from the cultivation of forests, inasmuch as its principle object consists in the production of nitrogen under any form capable of assimilation, whilst the object of forest culture is confined to the production of carbon." In both cases - as is not unusual-human intervention is at odds with the evolutionary history of the plant and, as such, is apt to lead to problems in long-term ecosystem, including planetary, function. This is one of the issues that Smil investigates in his interesting agriculturally based odyssey of human impact on natural ecosystem function.

Early farmers well knew of nitrogen's ecologic and economic importance (as organic matter) to crops long before the discovery of its biological importance as the backbone of proteins and nucleic acids in cells. So it was that early attempts at maximizing crop production focused on recycling "waste" such as human and farm animal urine and feces and on mixing leguminous crops with grain crops. Smil provides a fine brief history of these practices in Eurasia (but curiously leaves out similar practices by new world cultures like the Maya in Central America), noting that it was these practices that allowed for population densities of three to four people per hectare. To go to higher and extremely higher "sustainable" human population densities required nutrient imports (and, thus, energy), and this economic opportunity led to the rapid exploitation of guano-sea bird feces deposits-from islands along the Pacific coast of South America. The island deposits came about-as Smil neatly teaches-as a result of the unique ecology of nutrient upwelling along the South American Pacific coast leading to high ocean biological production rates, leading in turn to sustainable high bird populations with their high feces production, coupled with very low rainfalls leading to very low feces decomposition rates, leading to massive deposits of 
precious nitrogen-rich guano. Upon their discovery, they were rapidly exploited, leading to higher agriculture production in Europe and, later, elsewhere.

That supplies could not last forever (carrying capacity is a frequent ecological and evolutionary theme in Smil's story) was the driving force behind the quest to "split" the strongly bonded di-nitrogen $\left(\mathrm{N}_{2}\right)$ molecule, the natural form of inert atmospheric nitrogen. That the quest was led by old world scientists rather than new might be due to the relative brand-newness of agriculture in the very nutrient-rich new world compared to the relatively ancient practices of agriculture in the relatively nutrient-poor old world, which then set limits on human populations and their economic well-being. We do not know answers to these intriguing questions because the author did not explore them, concentrating, rather, on the evolution of scientific knowledge about nitrogen as it related to finding new chemical and technical ways to obtain its active forms for human use.

Having set the stage for the now insatiable human demand for biologically active $\mathrm{N}$-forms - ammonia $\left(\mathrm{NH}_{3}\right)$ and nitrate $\left(\mathrm{NO}_{3}{ }^{-}\right)$- Smil tells the story of the discovery of the Haber process wherein Fritz Haber in the first decade of the twentieth century successfully found the chemical and technical means to make efficient quantities of ammonia (from the basic reaction: $\mathrm{N}_{2}+3 \mathrm{H}_{2} \longrightarrow 2 \mathrm{NH}_{3}$ ) using catalysts and high temperatures and pressures (and so also high inputs of fossil fuel-derived energy). It was Carl Bosch who put the process into commercial practice. Both scientists won Nobel prizes for their work (an interesting postscript describes Haber's unapologetic leadership of the German Chemical Warfare Service during World War I, which resulted in 1.3 million casualties - including his wife Clara, by suicide, by war's end). Further innovation led to the commercial production of the various forms of ammonia (both for agriculture and military purposes) and of urea. Hydrogen $\left(\mathrm{H}_{2}\right)$ was also required for the process and so industrial - and further polluting - means of acquiring it were required. High temperature coke with water vapor was the original solution, but later methods relied on natural gas. All parts of the process generated - and still generate - copious quantities of waste $\mathrm{CO}_{2}$, and the connections to global warming and future environmental problems are not missed. It does not take too much imagination to also wonder about possible future evolutionary impacts, including extinctions and changes in environmental signals, leading to species decline.

Smil moves into a discussion of modern human dependence on nitrogen and some of its consequences. He states that, "...there is no way to grow crops, and human bodies without fixed nitrogen, and there are no bioengineered substitutes waiting to displace the Haber-Bosch synthesis and to supply the nutrient needed to grow food directly to crops." Having noted this, Smil enumerates the many problems of high production agriculture, including nutrient losses due to soil erosion and nutrient leaching and water pollution problems leading to not only human health issues (nitrates and other nitrogen-based water issues) but also to effects on wildlife and ecosystem function, especially eutrophication of water bodies as well as forested ecosystems-boreal and even temperate "...that have developed under constant (low) nitrogen stress." Here again, Smil's discussion of ecological impacts leads us to think of the possible future evolutionary ones as well.

Turning his attention to problems of human population growth rates, Smil makes this startling observation: "The range of our dependence on the Haber-Bosch synthesis of ammonia thus is as follows: for about $40 \%$ of humanity it now provides the very means of survival; only half as many people as are alive today could be supplied by prefertilizer agriculture...," and, "Now nearly 2.5 billion people are here because proteins in their bodies are built of amino acids whose nitrogen came-via plant and animal foods-from the Haber-Bosch synthesis. Virtually all the protein needed for the growth of 2 to 4 billion children to be born during the next two generations will have to come from the same source, from the synthesis of ammonia from its elements."

He mentions loss of natural habitats as problems arising due to the need for more space to feed future humans, but a feeling is generated that it is a problem subject to technical solutions. The same feeling occurs when considering depletion of fossil fuels, which will lead inevitably to higher costs in agricultural production, very certainly including fertilizer production, and which will in turn lead to higher food costs, likely starvation, and human deaths. Smil does not discuss this scenario. But, as an ecologist, I might venture to predict that as high energy fertilizer industries fall apart due to rising energy costs, so will human populations come down to carrying capacities appropriate to natural systems, which then could be the safety valve that allows for recovery of human-disturbed ecosystems and the gene systems that depend on them.

One solution to prevent future catastrophic human population loss due to lack of affordable limiting nutrients and energy is global public education in the environmental sciences - especially with/for women-which will then lead naturally to reduced global population pressures and then in turn lead to sustainable world agricultural systems that also include room for naturally evolved ecological systems as well.

This book makes for an excellent introductory puzzle for both ecology and evolution classes. Discussions of nitrogen limits to human populations, and the consequences of technical solutions to such limitations provide material for classroom discussions of basic chemistry and physics (first and second Laws of Thermodynamics) and the limits to growth. The topic also provides interesting material for 
discussion of the impacts of technology on the environment and speculation on their possible global evolutionary impacts. As one example, Smil's story of long-term guano deposits off the Pacific coast of Peru provides excellent avenues for students to explore puzzles of interconnections of geography and climate, nutrient cycles, and food chains and then mix in human population growth and its demand for greater agricultural production, leading in turn to impacts on natural ecosystems, thence, possible future evolutionary issues. If students put pieces of the puzzle together themselves, they are more likely to remember it and so pass those stories along to their own students and children, in turn, leading to a more stable and healthier global ecosystem. 